\title{
Gold nanoparticle-based sensing platform of hydrazine, sulfite, and nitrite for food safety and environmental monitoring
}

\author{
Govindhan Maduraiveeran ${ }^{1,2^{*}}$ and Ramasamy Ramaraj ${ }^{1^{*}}$
}

\begin{abstract}
Background: A facile and sensitive electrochemical sensor platform has been explored based on gold nanoparticles (Au NPs) dispersed in amine-functionalized three-dimensional (3D) silicate sol-gel network for ((aminopropyl)triethoxysilane (APS)-Au NPs) for multi-analytes such as hydrazine, sulfite, and nitrite.

Methods: Au NPs dispersed silicate network was prepared via a single-step chemical reduction strategy. The Au NPsbased sensor platform was fabricated through drop-cast on a glassy carbon (GC) electrode.

Results: The fabricated APS-Au NPs-based sensor was characterized by ultraviolet-visible (UV-Vis) spectroscopy, cyclic voltammetry (CV), and scanning electrochemical microscopy (SEM). The resultant sensor was employed for the electrocatalytic and sensor applications towards hydrazine, sulfite, and nitrite in $0.1 \mathrm{M}$ phosphate buffer (PB) (pH 7.2). The APS-Au NPs sensor exhibited an excellent catalytic activity in the absence of any other electron transfer mediators/enzyme immobilized at the electrode surface. The electrocatalytic oxidation of hydrazine, sulfite, and nitrite occurs at $\sim 40, \sim 170$, and $\sim 550 \mathrm{mV}$, respectively, which is lesser positive potential of $\sim 810, \sim 735$, and $\sim 393 \mathrm{mV}$ for the oxidation of hydrazine, sulfite, and nitrite, respectively, than that of the bare GC electrode. Moreover, the present sensor showed low detection limits of $10 \mathrm{nM}, 100 \mathrm{nM}$, and $1 \mu \mathrm{M}$ for hydrazine, sulfite, and nitrite respectively.
\end{abstract}

Conclusions: APS-Au NPs sensor highlights the successful design for sensitive detection of multi-target analytes for food safety and environmental monitoring applications.

Keywords: Gold nanoparticle, Silicate network, Modified electrode, Electrocatalysis, Electrochemical sensor

\section{Background}

Nanostructured materials offer a wide range of research and development possibilities in diverse areas of photonics, electronics, material science, catalysis, and sensors due to their high surface area to volume ratios and can easily be designed to improve the specific reaction and requirements (Alammari et al. 2015; Govindhan et al. 2016; Hu and Dai 2016). The metal and semiconductor nanoparticles has gained enormous interest on the electrochemical interfaces to develop the electrochemical nanoscale systems for various catalytic and sensor applications (Alammari et al. 2015; Keeley et al. 2016; Wang et al. 2016; Wang et al. 2015). The metal nanoparticles

\footnotetext{
* Correspondence: mgovindh@lakeheadu.ca; ramaraj@@yahoo.com ${ }^{1}$ School of Chemistry, Madurai Kamaraj University, Madurai 625 021, India Full list of author information is available at the end of the article
}

play a key role in catalytic and electrocatalytic reactions which may empower numerous functionalities to line up for the targeted applications because of the interactivity of essential nanostructured sensor elements with their immediate local environments (Chen and Chatterjee 2013; Govindhan et al. 2014, Huber et al. 2015; Maduraiveeran and Ramaraj 2009). Especially, gold nanoparticles (Au NPs) have found use in areas ranging from chemical separations and sensing to direct applications in the medical, food, and environmental community due to their unique chemical, optical, and electronic properties (Huber and Leopold 2016; Moghimi et al. 2015; Wang et al. 2015; Zhang et al. 2017).

In recent years, $\mathrm{Au}$ NPs have been the subject of strong interest in areas of materials science, environmental and energy science, biotechnology, and organic 
chemistry for their function as molecular markers, diagnostic imaging, catalysis, and sensors (Govindhan et al. 2015; Govindhan and Chen 2015; Sabri et al. 2014). In particular, Au NPs have received considerable devotion in various key electrocatalytic reactions and sensor applications towards $\mathrm{CO}$, methanol, oxygen, hydrogen peroxide, NADH, glucose, and catechol, and etc. (Govindhan et al. 2015; Maduraiveeran and Ramaraj 2007a, b; Zhang et al. 2015). The silica-based materials have been employed for the modification of the electrode surface among the wide range of materials, and they have attracted considerable attention for chemical and biological catalytic and sensing because of the high reactivity of the surface silane, groups, tunable porosity, high thermal stability, and chemical inertness, enabling the immobilization of different molecules through silane coupling chemistry (Bharathi and Lev 2000; Maduraiveeran and Ramaraj 2007a, b). In the 1980s, the sol-gel chemistry has been utilized for the fabrication of the modified metal such as gold $(\mathrm{Au})$, platinum $(\mathrm{Pt})$, and silver $(\mathrm{Ag})$ interfaces (Gong et al. 2014, Jena and Raj 2015, Sampath and Lev 1996). Numerous sensor platforms based on metal nanoparticles dispersed silicate matrices have been reported for environmental and biomedical applications (Adams et al. 2011; Jena and Raj 2007; Matsuhisa et al. 2013).

Hydrazine is widely used as high-energy propellants in rockets and spacecraft by the military, aerospace industries and fuel for zero-emission fuel cells, and it has been reported that hydrazine has been implicated in terrorist incident. Due to the carcinogenic and mutagenic effects, it is considered as a neurotoxin (Malik et al. 2016; Zhao et al. 2016). The poisoning of hydrazine causes vomiting, severe irritation of the respiratory tract, and eventually in long-term effects on the central nervous system. In addition, hydrazine is supposed to be oxidized by peroxidases in human body into reactive intermediates adept of affecting a variety of side effects containing DNA damage. Sulfites are sulfur-based preservatives that have been employed to prevent or reduce discoloration of lightcolored fruits and vegetables, prevent black spots on shrimp and lobster, inhibit the growth of microorganisms in fermented foods such as wine, condition dough, and maintain the stability and potency of certain medications. It is also used to bleach food starches to prevent rust and scale in boiler water that is used to steam food and even in the production of cellophane for food packaging. Owing to the antioxidant and inhibitory characteristics in enzymatic or microbial activity in beverage, food, and pharmaceutical products, sulfite is utilized as a preservative for various food and meat products (Amatatongchai et al. 2015; Grings et al. 2013; Zhou et al. 2014).

Nitrite is widely considered as nitrate's partner in environmental crime and in many respects can be measured to be the more dangerous of the two in terms of the potential influence of excessive concentrations on the health of humans and aquatic organisms. In many cases, nitrite is used as a preservative compound in numerous food materials and products, and it is present widely in the environment, beverages, and food products (Quan et al. 2005; Quan and Shin 2010). Therefore, the development of effective catalytic and sensing methods for the detection of hydrazine, sulfite, and nitrite is essential due to their importance in industry, food, water, and biological fluids and its toxicity. Among other analytical methods, electrochemical methods are embryonic in self-contained, compact, and low cost, with minimal power requirements. In addition, electrochemical sensor offers rapid response and high sensitivity and selectivity providing quantitative analytical information.

It is an effort to develop an Au nanostructure-based electrochemical sensor platform for the sensitive detection of multiple toxic analytes such as hydrazine, sulfite, and nitrite, which usually exist in food products and environment. A simple and effective sensor platform is explored based on APS-Au NPs modified glassy carbon (GC) electrode in neutral solution with less positive electrochemical potential, which reduce enormous electrochemical oxidation potential without any enzymes immobilized on the electrode surface. Furthermore, the developed sensor platform is productively tested for the sensitive detection of hydrazine, sulfite, and nitrite in $0.1 \mathrm{M} \mathrm{PB}$ (pH 7.2). The APS-Au NPsmodified GC electrode exhibited less positive oxidation potential, rapid response, and low detection limit towards hydrazine, sulfite, and nitrite.

\section{Methods}

\section{Materials}

(3-(Aminopropyl)triethoxysilane and hydrogen tetrachloroaurate were purchased from Aldrich. Hydrazine, sulfite, and nitrite were purchased from Merck, and freshly prepared analytes of hydrazine, sulfite, and nitrite were utilized for all catalytic and sensor measurements. For all experiments, doubly distilled water was used and all glassware were carefully cleaned with aqua regia (3:1 $\left.\mathrm{HNO}_{3} / \mathrm{HCl}(v / v)\right)$ and rinsed extensively with doubly distilled water before use.

\section{Measurements}

The electrochemical experiments were performed using a EG\&G PAR 283A Potentiostat/Galvanostat controlled by the M270 software. A conventional two-compartment three-electrode cell was used for all electrochemical measurements studied. The reference electrode was a $\mathrm{Ag} / \mathrm{AgCl}$ electrode. GC electrode was employed as the working electrode with a diameter of $3 \mathrm{~mm}$ and platinum foil utilized as the counter electrode. The GC electrode was twice physically polished with alumina powder 
(200-300 mesh) followed by sonication in double distilled water for $3 \mathrm{~min}$. All electrochemical experiments were conducted in deaerated $0.1 \mathrm{M} \mathrm{PB}$ at $\mathrm{pH}$ 7.2. Agilent 8453 diode array UV-visible spectrophotometer was used for UV-Vis measurements. The surface characterization was studied by scanning electron microscopy (SEM) images with a HITACHI MODEL S-3000H scanning electron microscope. All the electrochemical experiments were performed with freshly prepared solutions, and nitrogen was used to deaerate all experimental solutions.

\section{Fabrication of sensor platform}

APS-Au NPs were synthesized by a simple chemical reduction strategy (Bharathi et al. 1999). In typical, total of $10 \mathrm{~mL}$ of sol with molar ratios of 100:0.1, 100:1, and 100:10 (3-(aminopropyl)triethoxysilane (APS)/ $/ \mathrm{HACl}_{4}$ ) were prepared by dissolving appropriate amount of APS and $\mathrm{Au}$ salt in methanol and $1 \mathrm{~mL}$ of $0.01,0.1$, and 1.0 $\mathrm{M} \mathrm{HAuCl}_{4}$. A clear yellow-colored solution was obtained and the solution. The primary mixture of precursors was sonicated for $10 \mathrm{~min}$ and then $0.1 \mathrm{~mL}$ of $0.1 \mathrm{M} \mathrm{HCl}$ and $1 \mathrm{~mL}$ of water were added to the solution. A freshly prepared $0.05 \mathrm{~mL} 5 \% \mathrm{NaBH}_{4}$ was added to the mixture to reduce the $\mathrm{HAuCl}_{4}$. For the preparation of GC electrode modified with APS-Au NPs (designated as APS-Au NPs electrode), the colloidal solution of the as-synthesized APS-Au NPs was coated on the cleaned GC electrode surface by taking $5 \mu \mathrm{L}$ of APS-Au NPs and then allowed to dry in air. The resulted APS-Au NPs modified electrode was employed for further electrochemical measurements.

\section{Results and discussion}

\section{Characterization of APS-Au NPs}

UV-visible absorbance spectroscopy was employed for the optical characterization of the prepared APS-Au NPs in solution as well as the film. As shown in Fig. 1a, the collective excitation of the free electrons of the APS-Au NPs in solution produced the surface plasmon band at $516 \mathrm{~nm}$. The surface plasmon resonance (SPR) absorption band showed at $520 \mathrm{~nm}$ for the APS-Au NPs film coated on the glass slide revealed that the Au NPs were stable. The gold nanoparticle size was not altered in the film state, which is clearly seen in Fig. 1a (inset). A 4-nm redshift in the SPR absorption band was observed for the $\mathrm{Au}$ NPs due to the APS silicate sol-gel binding on the Au NPs.(Chen et al. 2015) The electrochemical behavior of the APS-Au NPs at the GC electrode was studied to understand the electrical communication between the APS-Au NPs in the film at the GC electrode surface.

The CV response of the APS-Au NPs electrode was recorded in $0.1 \mathrm{M} \mathrm{H}_{2} \mathrm{SO}_{4}$. The APS-Au NPs electrode exhibited a sharp oxidation peak at $\sim 920 \mathrm{mV}$ and a reduction peak at $\sim 470 \mathrm{mV}$, which was the characteristic of the reduction of surface oxides of Au (Fig. 1b). This result suggested that the Au NPs were strongly immobilized in APS silicate sol-gel film and they were in electrical contact with each other. The charge efficiency (CE) is defined as the ratio between the anodic $\left(Q_{a}\right)$ and cathodic process $\left(Q_{c}\right)$ as $C E=Q_{a} / Q_{c}=7$ (Ghilane et al. 2007). Moreover, the higher value of charge efficiency suggests that more amounts of Au NPs were immobilized inside the silicate sol-gel network.
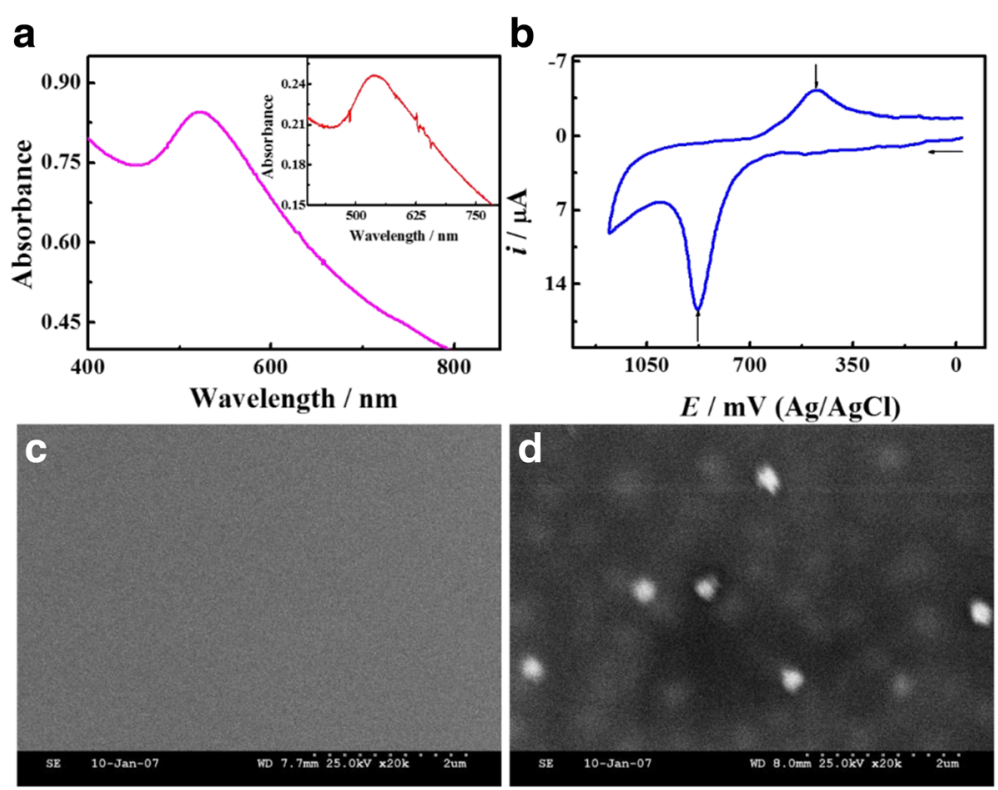

Fig. 1 a Absorption spectrum of APS-Au NPs in solution. Inset: absorption spectrum of APS-Au NPs film coated on glass slide. $\mathbf{b}$ CV curve of the APS-Au NPs electrode recorded in $0.1 \mathrm{M} \mathrm{H}_{2} \mathrm{SO}_{4}$, at a scan rate of $50 \mathrm{mVs}^{-1}$. SEM images of the $\mathbf{c}$ APS and $\mathbf{d}$ APS-Au NPs film 
The surface morphology of the APS-Au NPs film was examined by SEM. Figure 1c, d displays the SEM images observed for APS silicate sol-gel film and Au NPs embedded in APS silicate sol-gel network respectively. The image of the plain APS silicate sol-gel network showed a clear image, as shown in Fig. 1c. Figure 1d clearly displays the uniform distribution of Au NPs throughout the APS silicate sol-gel network. The Au NPs buried inside the silicate sol-gel film are clear with haze/blur image, as depicted in Fig. 1d.

\section{Electrochemical hydrazine sensor}

The developed APS-Au NPs electrode was tested for the electrocatalytic oxidation of $250 \mu \mathrm{M}$ hydrazine in $0.1 \mathrm{M}$ $\mathrm{PB}$ (pH 7.2). Figure 2a shows the CV curves obtained for the electrocatalytic oxidation of hydrazine at different amounts of Au NPs dispersed in the APS silicate sol-gel matrix. The presence of the lower amount of Au NPs $(\mathrm{Si}: \mathrm{Au}=100: 0.1))$ in the silicate film showed an ill-defined voltammogram, as shown in Fig. 2a. Even the higher amount of $\mathrm{Au}$ NPs embedded in the silicate network (Si:Au $=100: 10)$ showed a $\sim 50 \mathrm{mV}$ more positive potential shift with a small decrease in the anodic current for hydrazine oxidation (Fig. 2a when compared to the ratio of $\mathrm{Si}: \mathrm{Au}=100: 1$ in APS-Au NPs electrode (Fig. 2a). The excellent electrocatalytic activity was observed for the oxidation of hydrazine at the APS-Au NPs with $\mathrm{Si}: \mathrm{Au}=$ 100:1. The molar ratio of Si:Au = 100:1 (APS-Au NPs) was optimized ratio for the oxidation of hydrazine.
The rate of heterogeneous electrochemical reaction of hydrazine oxidation was calculated (Maduraiveeran and Ramaraj 2007b) from the CV data as $8.46 \times 10^{-4} \mathrm{~mol} \mathrm{~s}^{-1}$ $\mathrm{cm}^{-2}$ at the APS-Au NPs electrode. The electrocatalytic activity of Au NPs on the electrode surface mainly depends on the amount of Au NPs dispersed in the APS silicate sol-gel network. For the controlled experiments, the electrochemical oxidation of hydrazine was tested at the bare GC electrode. As shown in Additional file 1: Figure $\mathrm{S} 1 \mathrm{~A}$, the oxidation of hydrazine was occured at $\sim 850 \mathrm{mV}$ at the bare GC electrode. Interestingly, the hydrazine oxidation at the APS-Au NPs modified GC electrode occurred at $\sim 40 \mathrm{mV}$, which is $\sim 810 \mathrm{mV}$ less positive than that of the bare GC electrode. It is interesting to observe such a very large decrease in the oxidation potential in the absence of any redox mediator at the modified electrode. This result suggests that the APS-Au NPs electrode showed excellent electrocatalytic activity towards the hydrazine oxidation. The large decrease in the electrochemical hydrazine oxidation potential with a substantial increase in the anodic current suggested a faster electron transfer reaction on the APS-Au NPs owing to the high catalytic effect of the Au NPs, which led to a sharper and more well-defined peak.

The effect of scan rate was explored where a gentle increase in peak current was observed at the APS-Au NPs electrode for the electrocatalytic oxidation of hydrazine as shown in Fig. 2b. The corresponding plot of the
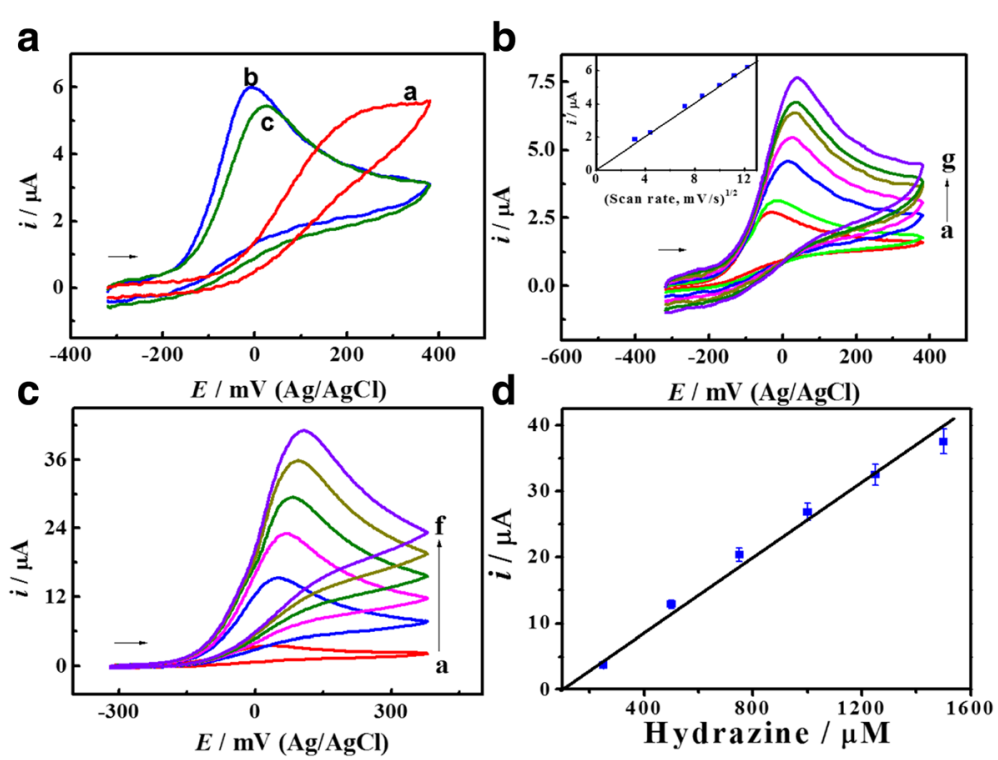

Fig. 2 a CV curves of the APS-Au NPs (Si:Au = 100:0.1 (a), 100:1 (b), and 100:10 (c)) electrodes recorded for $250 \mu$ M of hydrazine at a scan rate of $50 \mathrm{mV} \mathrm{s}^{-1}$. b CV curves of the APS-Au NPs (Si:Au=100:1) electrode with different scan rates of 10 (a), 20 (b), 50 (c), 75 (d), 100 (e), 125 $(f)$, and $150(\mathrm{~g}) \mathrm{mV} \mathrm{s}^{-1}$ for $250 \mu \mathrm{M}$ hydrazine. Inset: the plot of anodic peak current against square root of scan rate. c CV curves of the APS-Au NPs (Si:Au= 100:1) electrode recorded for 250 (a), 500 (b), 750 (c), 1000 (d), 1250 (e), and $1500 \mu \mathrm{M}(f)$ of hydrazine at $50 \mathrm{mV} \mathrm{s}{ }^{-1}$. Electrolyte, $0.1 \mathrm{M} \mathrm{PB}(\mathrm{pH}$ 7.2). d The corresponding calibration plot 
anodic peak current against the square root of the scan rate showed a linear response (Fig. $2 b$ (inset)). This result indicates that the electron transfer process was a diffusion-controlled one. Figure $2 \mathrm{c}$ shows the $\mathrm{CV}$ curves of the APS-Au NPs electrode recorded for the every addition of $250 \mu \mathrm{M}$ hydrazine into $0.1 \mathrm{M}$ PB electrolyte solution led to an increase in the anodic peak current steadily at the APS-Au NPs electrode (Fig. 2d). Amperometric $i-t$ technique was further used for the sensitive sensing of hydrazine at the APS-Au NPs electrode.

Figure $3 \mathrm{a}, \mathrm{c}$ displays the amperometric responses of the APS-Au NPs electrode towards the sensing of hydrazine at the nano- and micromolar ranges. The APS-Au NPs electrode was polarized at $50 \mathrm{mV}$, and aliquots of hydrazine were injected into a stirred supporting electrolyte solution. A rapid increase in the anodic peak current was noticed after each addition of hydrazine into the solution, and a steady-state response was attained within $3 \mathrm{~s}$. The rapid response indicates that the fast electron transfer occurred at the electrode surface. The APS-Au NPs electrode was found to be highly sensitive, and the amperometric response was very stable, which offered a linear dependence over a wide range of hydrazine concentrations $(10 \mathrm{nM}-12 \mu \mathrm{M})$. The sensitivity was found to be $0.03 \mathrm{nA} / \mathrm{nM}$ with a correlation coefficient of 0.99 , and the experimental lowest detection limit was found to be $10 \mathrm{nM}$. The sensitivity of the sensor is related to the efficiency of the preconcentration of the target analyte at the electrode, and the efficiency of the electrochemical process in turn depends on the accessible surface area of the working electrode.

\section{Electrochemical sulfite sensor}

The electrocatalytic oxidation of sulfite was explored at the APS-Au NPs electrode. Figure 4a shows the CVs obtained for the oxidation of sulfite in the presence of different amounts of Au NPs in the APS silicate matrix. The $\mathrm{Au}$ NPs (Si:Au = 100:0.1) electrode showed an ill-defined voltammogram, as shown in Fig. 4a. The presence of high amount of Au NPs in the silicate network ( $\mathrm{Si}: \mathrm{Au}=100: 10)$ exhibited an anodic peak at $\sim 300 \mathrm{mV}$, which is a more positive potential shift with a small decrease in the anodic peak current for sulfite oxidation (Fig. 4a) when compared to $\mathrm{Si}: \mathrm{Au}=100: 1$ in APS-Au NPs electrode (Fig. 4a). The APS-Au NPs ( $\mathrm{Si}: \mathrm{Au}=100: 1)$ electrode showed a welldefined voltammetric response held at $\sim 170 \mathrm{mV}$ for the oxidation of sulfite. The bare GC electrode exhibited an oxidation peak at $\sim 905 \mathrm{mV}$ towards sulfite oxidation, as shown in Additional file 1: Figure S1B. The APS-Au NPs ( $\mathrm{Si}: \mathrm{Au}=100: 1)$ electrode showed lesser positive oxidation potential for sulfite about $735 \mathrm{mV}$ than that of the bare $\mathrm{GC}$ electrode. The rate of the electrode reaction was estimated to be $3.24 \times 10^{-4} \mathrm{~mol} \mathrm{~s}^{-1} \mathrm{~cm}^{-2}$ at the APS-Au NPs electrode for the oxidation of sulfite.

The effect of the scan rate was studied at the APS-Au NPs electrode. A gentle increase in the peak current was observed with an increase in the square root of the scan rate at the APS-Au NPs electrode as displayed in Fig. $4 \mathrm{~b}$. The inset in Fig. 4b shows the plot of anodic current against the square root of the scan rate, which showed a linear response. The obtained linear response was due to the attribution of the diffusion-controlled electron transfer process occurred at the surface of the APS-Au NPs
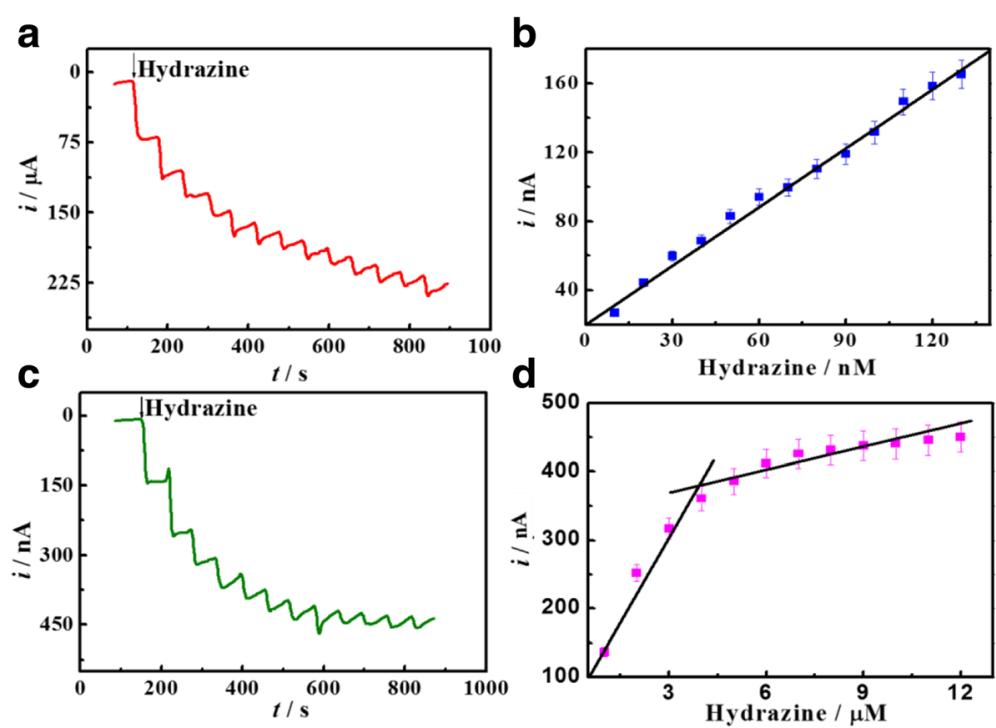

Fig. 3 Amperometric response of the APS-Au NPs electrode recorded for the sensing of hydrazine upon each addition of a $10 \mathrm{nM}$ and $\mathbf{c} 1 \mu \mathrm{M}$ of hydrazine at regular interval. b, d The corresponding calibration plots 

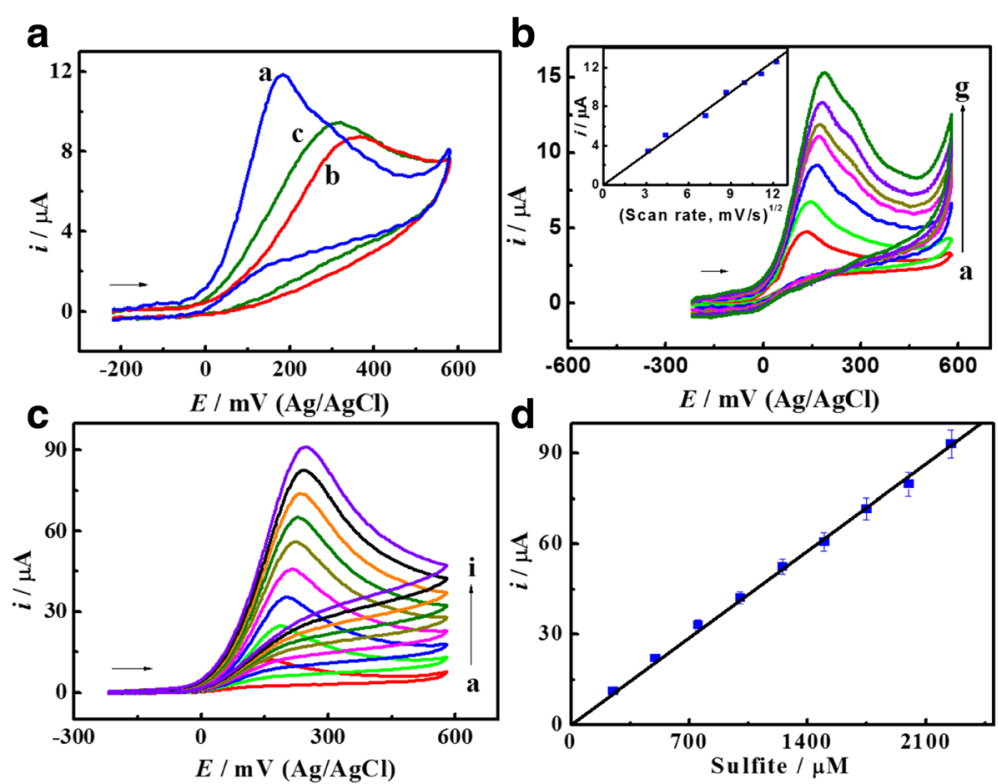

Fig. 4 a CV curves of the APS-Au NPs (Si:Au=100:0.1 (a), 100:1 (b), and 100:10 (c)) electrodes recorded for $250 \mu M$ of sulfite at a scan rate of $50 \mathrm{mV} \mathrm{s}^{-1}$. b CV curves of the APS-Au NPs (Si:Au=100:1) electrode with different scan rates of 10 (a), 20 (b), 50 (c), 75 (d), 100 (e), 125 ( $f$ ) and 150 (g) $\mathrm{mV} \mathrm{s}^{-1}$ for $250 \mu \mathrm{M}$ sulfite. Inset: the plot of anodic peak current against the square root of scan rate. $\mathbf{c}$ CV curves of the APS-Au NPs (Si:Au =

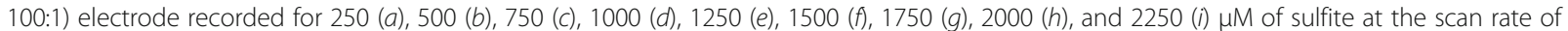
$50 \mathrm{mV} \mathrm{s}^{-1}$. Electrolyte, $0.1 \mathrm{M} \mathrm{PB}(\mathrm{pH}$ 7.2). d The corresponding calibration plot

electrode. Figure 4c displays the CV curves recorded for various high concentrations of sulfite at the APS-Au NPs electrode. With each addition of $250 \mu \mathrm{M}$ sulfite, the anodic current was increased steadily at the APS-Au NPs electrode. A straight line was obtained in the range of $250 \mu \mathrm{M}-2.25 \mathrm{mM}$ sulfite when the anodic peak current was plotted against the concentrations of sulfite (Fig. 4d).
Figure 5a, c presents the amperometric curves of the APS-Au NPs electrode towards the sensing of sulfite in various concentrations ranges, which was polarized at $200 \mathrm{mV}$. The various concentration of sulfite was injected into a stirred 0.1 M PB (pH 7.2). After each addition of sulfite into the electrolyte solution, an increase in the anodic peak was noticed. A steady-state

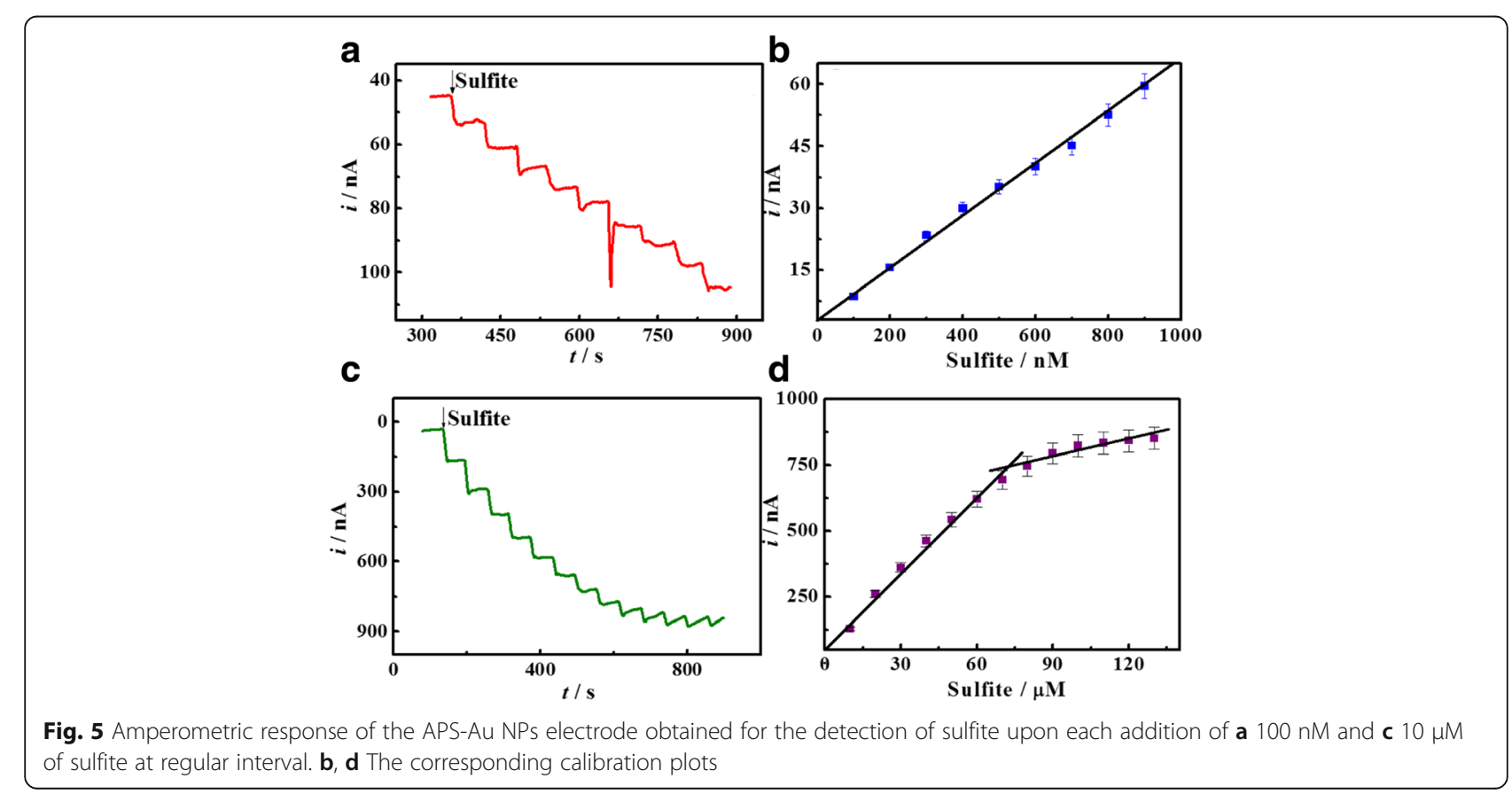


response was attained $\sim 4 \mathrm{~s}$. The APS-Au NPs electrode was highly sensitive, which offered a linear dependence over a wide range of sulfite concentrations from $100 \mathrm{nM}$ to $150 \mu \mathrm{M}$. The sensitivity was found to be $0.001 \mathrm{nA} /$ $\mathrm{nM}$ with a correlation coefficient of 0.99 , and the low detection limit was experimentally found to be $100 \mathrm{nM}$.

\section{Electrochemical nitrite sensor}

Furthermore, the electrochemical sensing of nitrite was performed with as-established APS-Au NPs electrode. Figure 6a presents the CV curves of the APS-Au NPs electrode for the oxidation of nitrite in the presence of different amounts of Au NPs at the electrode surface. The dispersion of APS-Au NPs with $\mathrm{Si}: \mathrm{Au}=100: 0.1$ at the surface of the GC electrode showed a less pronounced CV curve, as displayed in Fig. 6a. When an increase in the ratio of $\mathrm{Si}: \mathrm{Au}=100: 1$ was employed at the APS-Au NPs electrode, a higher anodic peak current was observed when compared to the APS-Au NPs ( $\mathrm{Si}: \mathrm{Au}=100: 0.1$ and 100:10) electrode. The APS-Au NPs $(\mathrm{Si}: \mathrm{Au}=100: 1)$ electrode exhibited a better electrocatalytic activity for the oxidation of nitrite when compared to the other two electrodes presented in the study. The maximum catalytic current and lowering of oxidation potential were observed at the APS-Au NPs electrode ( $\mathrm{Si}: \mathrm{Au}=100: 1)$ electrode. The dispersion of Au NPs with different amounts in the silicate sol-gel film can influence the electrocatalytic activity towards nitrite significantly.
A well-defined voltammetric oxidation peak at $\sim 550 \mathrm{mV}$ was observed for the oxidation of nitrite at the APS-Au NPs electrode (Fig. 6a) which is $\sim 393 \mathrm{mV}$ less positive than that at the bare GC electrode (Additional file 1: Figure S1C). No characteristic response was observed for the oxidation of nitrite in the potential window used at the bare GC. This decrease in the oxidation potential for nitrite was observed in the absence of any other redox mediator at the APS-Au NPs electrode. The APS-Au NPs as film on the electrode surface acted as nanoelectrode and facilitated the electron transfer process and decreased the oxidation potential enormously towards nitrite. This implies that the electrode possessed an excellent electrocatalytic activity towards the nitrite oxidation. The rate of nitrite oxidation reaction was calculated as $2.81 \times 10^{-4} \mathrm{~mol} \mathrm{~s}^{-1} \mathrm{~cm}^{-2}$ at the APS-Au NPs electrode.

Figure $6 \mathrm{~b}$ shows the $\mathrm{CV}$ curves recorded for the oxidation of nitrite with increasing the scan rate. With an increase in the scan rate, a gentle increase in the peak current was observed at the APS-Au NPs electrode, as presented in the Fig. $6 \mathrm{~b}$ inset. The plot of the anodic current against the square root of the scan rate depicted a linear response, which suggested that the obtained electron transfer process was diffusion-controlled at the electrode surface. Figure $6 \mathrm{c}$ shows the $\mathrm{CV}$ curves of the APS-Au NPs electrode recorded for various concentrations of nitrite at the APS-Au NPs electrode. With each addition of $250 \mu \mathrm{M}$ nitrite into $0.1 \mathrm{M} \mathrm{PB}$, the anodic peak current
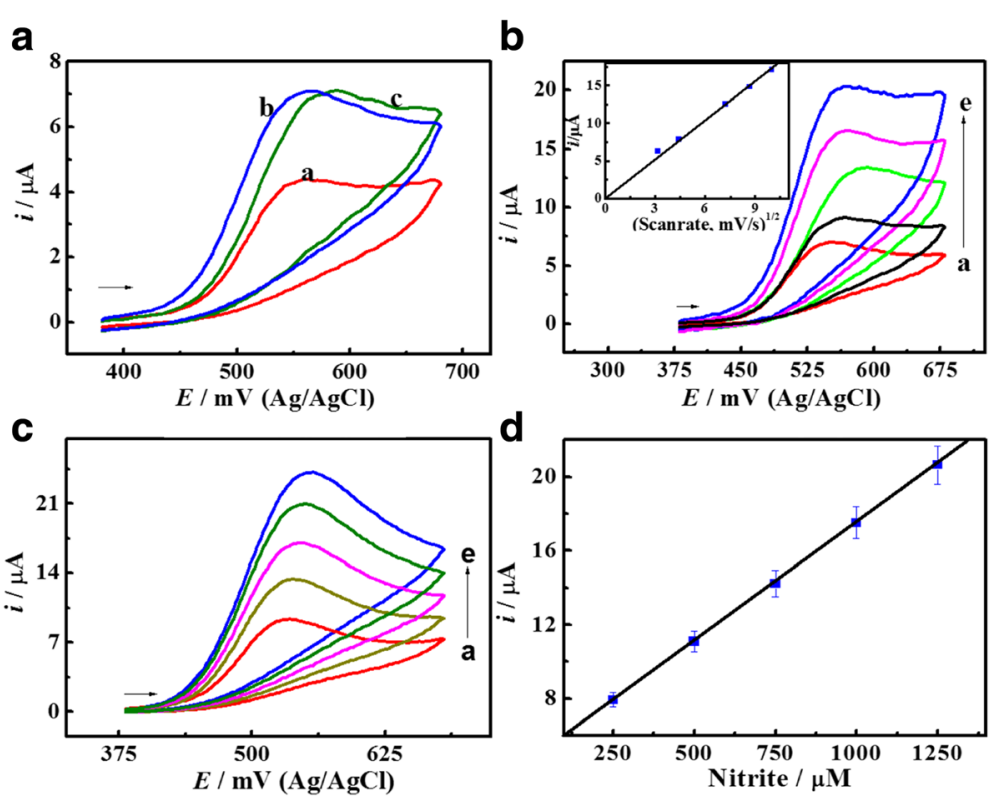

Fig. 6 a CV curves of the APS-Au NPs (Si:Au = 100:0.1 (a), 100:1 (b), and 100:10 (c)) electrodes recorded for $250 \mu M$ of nitrite at a scan rate of $50 \mathrm{mV} \mathrm{s}^{-1} . \mathbf{b}$ CV curves of the APS-Au NPs (Si:Au = 100:1) electrode with different scan rates of $10(a), 20(b), 50(c), 75$ (d), 100 (e), 125 (f), and 150 (g) $\mathrm{mV} \mathrm{s}^{-1}$ for $250 \mu \mathrm{M}$ nitrite. Inset: the plot of anodic peak current against the square root of scan rate. c CV curves of the APS-Au NPs (Si:Au = 100:1) electrode recorded for $250(a), 500(b), 750(c), 1000(d)$ and $1250 \mu \mathrm{M}(e)$ of nitrite at the scan rate of $50 \mathrm{mV} \mathrm{s}^{-1}$. Electrolyte, $0.1 \mathrm{M} \mathrm{PB}(\mathrm{pH} 7.2)$. d The corresponding calibration plot 

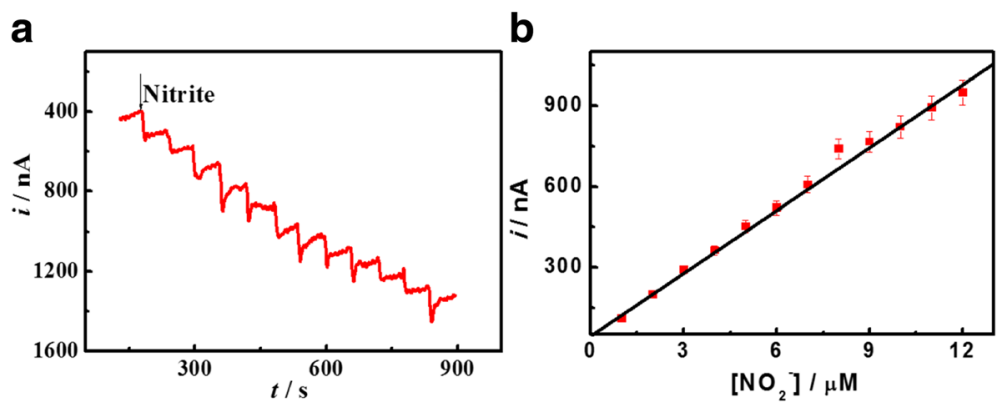

Fig. 7 Amperometric response of the APS-Au NPs electrode measured for the sensing of nitrite upon each addition of $1 \mu M(\mathbf{a})$ of nitrite at regular interval. The corresponding calibration plots (b)

was increased. The calibration plot (Fig. 6d) showed a straight line when the anodic peak current was plotted against the concentrations of nitrite in the range of $250 \mu \mathrm{M}-1.25 \mathrm{mM}$.

Figure 7a displays the amperometric response observed at the APS-Au NPs electrode towards the sensing of nitrite. The APS-Au NPs electrode was polarized at $600 \mathrm{mV}$, and the aliquots of nitrite were injected into a stirred electrolyte solution. A fast increase in the anodic current was noticed after each addition of $1 \mu \mathrm{M}$ of nitrite into the solution, and a steady-state response was attained less than 3 s. The APS-Au NPs electrode showed high sensitivity of $21.6 \mathrm{nA} / \mu \mathrm{M}$ with a correlation coefficient of 0.99 . The electrochemical sensing of nitrite offered a linear dependence over the range of $1-12 \mu \mathrm{M}$ nitrite. The experimental low detection limit was found to be $1 \mu \mathrm{M}$. The amperometric sensing property of the APS-Au NPs electrode was summarized in Table 1. The effect of interferences was also performed at the studied APS-Au NPs electrode. The active interferences are majorly presented in the environmental water, including of $0.01 \mathrm{M}$ sulfate, nitrate, and other organic compound of benzene. The amperometric response suggested that the developed sensor platform exhibited high selectivity. Moreover, the present sensor was stable for more than 20 days at room temperature, and the results were reproducible.

\section{Conclusions}

In summary, a three-dimensional amine-functionalized APS silicate sol-gel network-stabilized Au NPs-based electrochemical sensor platform is successfully developed in the absence of any other immobilized redox

Table 1 The sensor parameters are listed

\begin{tabular}{lllll}
\hline Analytes & Method & LOD & Sensitivity & Linear range \\
\hline Hydrazine & Amperometry & $10 \mathrm{nM}$ & $0.031 \mathrm{nA} / \mathrm{nM}$ & $10 \mathrm{nM}-12 \mu \mathrm{M}$ \\
Sulfite & Amperometry & $100 \mathrm{nM}$ & $0.001 \mathrm{nA} / \mathrm{nM}$ & $100 \mathrm{nM}-150 \mu \mathrm{M}$ \\
Nitrite & Amperometry & $1 \mu \mathrm{M}$ & $21.60 \mathrm{nA} / \mu \mathrm{M}$ & $1-12 \mu \mathrm{M}$ \\
\hline
\end{tabular}

mediator/enzyme for hydrazine, sulfite, and nitrite. The fabricated electrocatalyst exhibits a large decrease in the electrochemical oxidation potential towards those analytes. Our experimental results reveal that the direct electrocatalytic performance of the Au NPs in APS silicate network is successfully utilized towards the detection of hydrazine, sulfite, and nitrite with low detection limits of $10 \mathrm{nM}, 100 \mathrm{nM}$, and $1 \mu \mathrm{M}$, respectively, from the amperometric experimental evidences. This simple sensor platform concretes the tactic for the fabrication of $\mathrm{Au}$ NPs-based effective electrocatalytic platform for various environmental and food safety applications.

\section{Significance of the present study}

Sensing of hydrazine, sulfite, and nitrite has attracted considerable attention in the chemical, pharmaceutical, agricultural, and food industries. The development of sensitive analytical methods for the detection and determination of hydrazine, sulfite, and nitrite is essential due to their importance in industry, food, water, and biological fluids and its toxicity. Numerous methods such as spectrophotometry, fluorimetry, and chromatography have been reported for the detection of hydrazine, sulfite, and nitrite. Among other analytical techniques, electrochemical sensors are embryonic in self-contained, compact, and low cost, with minimal power requirements. The electrochemical sensor also offers rapid response, high sensitivity, and selectivity providing quantitative analytical information. Owing to the unique chemical, optical, and electronic properties, Au nanoparticles have attracted much attention in electrocatalysis and sensor platforms. The metal nanoparticles embedded in silica-based materials have been utilized for the electrode modification among the wide range of materials due to their attractive chemical and biological sensing properties, high reactivity of the surface silane, groups, tunable porosity, high thermal stability, and chemical inertness, enabling the immobilization of different molecules through silane coupling chemistry. 
In the present study, we have fabricated Au nanoparticles entrenched in amine-functionalized three-dimensional (3D) silicate sol-gel network (APS-Au NPs)-based electrochemical sensor platform through a facile chemical synthetic strategy for the sensitive detection of hydrazine, sulfite, and nitrite. The as-developed sensor platform exhibited an excellent direct electrocatalytic activity towards the oxidation of hydrazine, sulfite, and nitrite in the absence of any other electron transfer mediators/enzyme immobilization at the electrode surface and employed as a sensitive sensor for the detection and determination of hydrazine, sulfite, and nitrite. The APS-Au NPs displayed less positive potential of $\sim 810, \sim 735$, and $\sim 393 \mathrm{mV}$ for the electrocatalytic oxidation of hydrazine, sulfite, and nitrite, respectively, in comparison to the bare glassy carbon (GC) electrode surface. The experimental amperometric detection limit was found to be $5 \mathrm{nM}, 10 \mathrm{nM}$, and $1 \mu \mathrm{M}$ for hydrazine, sulfite, and nitrite at the APS-Au NPs-modified electrode surface. The large decrease in the over potential with a substantial increase in the peak current and high sensitivity may be associated with a faster electron transfer reaction at the APS-Au NPs electrode due to the high catalytic effect of the Au NPs and the nanoelectrode ensembles. The present study possessed major advantages of rapid response, low detection limits, high sensitivity and stability, capability of sensing multi-analytes for environment security, and food safety. We hope this manuscript would attract readers in the field of nanomaterial-based electrochemistry and be suitable for Journal of Analytical Science and Technology.

\section{Additional file}

Additional file 1: Figure S1. CV curves of the bare GC electrode recorded for the absence (dotted line) and the presence (solid line) of $250 \mu \mathrm{M}$ hydrazine (A), sulfite (B), and nitrite (C) in $0.1 \mathrm{M} \mathrm{PB}(\mathrm{pH} 7.2)$, at a scan rate of $50 \mathrm{mV} \mathrm{s}^{-1}$. (DOCX $419 \mathrm{~kb}$ )

\section{Abbreviations}

APS: (Aminopropyl)triethoxysilane; Au NPs: Gold nanoparticles; CV: Cyclic voltammetry; GC: Glassy carbon; SEM: Scanning electron microscopy

\section{Acknowledgements}

RR acknowledges the Department of Science and Technology (DST) for the financial support.

\section{Authors' contributions}

This work was designed by GM and RR. The experimental work and analysis of the results were done by GM. This manuscript was written by GM and RR. Both authors read and approved the final manuscript.

\section{Competing interests}

The authors declare that they have no competing interests.

\section{Author details}

${ }^{1}$ School of Chemistry, Madurai Kamaraj University, Madurai 625 021, India. ${ }^{2}$ Research Institute, Department of Chemistry, SRM University, Chennai, Tamil Nadu -603 203, India.
Received: 18 November 2016 Accepted: 16 February 2017

Published online: 22 June 2017

\section{References}

Adams KL, Jena BK, Percival SJ, et al. Highly sensitive detection of exocytotic dopamine release using a gold-nanoparticle-network microelectrode. Anal Chem. 2011:83:920-7.

Alammari W, Govindhan $\mathrm{M}$, Chen A. Modification of $\mathrm{TiO}_{2}$ nanotubes with PtRu/ graphene nanocomposites for enhanced oxygen reduction reaction. Chem Electro Chem. 2015;2:2041-7.

Amatatongchai M, Sroysee W, Chairam S. Simple flow injection for determination of sulfite by amperometric detection using glassy carbon electrode modified with carbon nanotubes-PDDA-gold nanoparticles. Talanta. 2015;133:134-41.

Bharathi S, Lev O. Sol-gel-derived prussian blue-silicate amperometric glucose biosensor. Appl Biochem Biotechnol. 2000:89:209-16.

Bharathi S, Fishelson N, Lev O. Direct synthesis and characterization of gold and other noble metal nanodispersions in sol-gel-derived organically modified silicates. Langmuir. 1999;15:1929-37.

Chen A, Chatterjee S. Nanomaterials based electrochemical sensors for biomedical applications. Chem Soc Rev. 2013;42:5425-38.

Chen $H$, Zhao $L$, Chen $D$, et al. Stabilization of gold nanoparticles on glass surface with polydopamine thin film for reliable LSPR sensing. J Colloid Interface Sci. 2015;460:258-63.

Ghilane J, Fan FR, Bard AJ, et al. Facile electrochemical characterization of core/shell nanoparticles. Ag core/Ag(2)O shell structures. Nano Lett. 2007;7:1406-12.

Gong K, Zhang M, Yan Y, et al. Sol-gel-derived ceramic-carbon nanotube nanocomposite electrodes: tunable electrode dimension and potential electrochemical applications. Anal Chem. 2014;76:6500-05.

Govindhan M, Chen A. Simultaneous synthesis of gold nanoparticle/graphene nanocomposite for enhanced oxygen reduction reaction. J Power Sources. 2015;274:928-36.

Govindhan M, Adhikari BR, Chen A. Nanomaterials-based electrochemical detection of chemical contaminants. RSC Adv. 2014;4:63741-60.

Govindhan M, Amiri M, Chen A. Au nanoparticle/graphene nanocomposite as a platform for the sensitive detection of NADH in human urine. Biosens Bioelectron. 2015;66:474-80.

Govindhan M, Mao B, Chen A. Novel cobalt quantum dot/graphene nanocomposites as highly efficient electrocatalysts for water splitting. Nanoscale. 2016;8:1485-92.

Grings M, Moura AP, Parmeggiani B, et al. Disturbance of brain energy and redox homeostasis provoked by sulfite and thiosulfate: potential pathomechanisms involved in the neuropathology of sulfite oxidase deficiency. Gene. 2013;531:191-8.

Hu C, Dai L. Carbon-based metal-free catalysts for electrocatalysis beyond the ORR. Angew Chem Int Ed Engl. 2016;55:11736-58.

Huber J, Leopold K. Nanomaterial-based strategies for enhanced mercury trace analysis in environmental and drinking waters. Trends in Anal Chem. 2016:80:280-92.

Huber TM, Navickas E, Friedbacher G, et al. Apparent oxygen uphill diffusion in $\mathrm{La}_{0.8} \mathrm{Sr}_{0.2} \mathrm{MnO}_{3}$ thin films upon cathodic polarization. Chem Electro Chem. 2015;2:1487-94.

Jena BK, Raj CR. Synthesis of flower-like gold nanoparticles and their electrocatalytic activity towards the oxidation of methanol and the reduction of oxygen. Langmuir. 2007;23:4064-70.

Jena BK, Raj CR. Au nanoparticle decorated silicate network for the amperometric sensing of isoniazid. Talanta. 2015;80:1653-56.

Keeley GP, Cherevko S, Mayrhofer KJ. The stability challenge on the pathway to low and ultra-low platinum loading for oxygen reduction in fuel cells. Chem Electro Chem. 2016:3:51-4.

Maduraiveeran G, Ramaraj R. A facile electrochemical sensor designed from gold nanoparticles embedded in three-dimensional sol-gel network for concurrent detection of toxic chemicals. Electrochem Commun. 2007a;9:2051-55.

Maduraiveeran G, Ramaraj R. Gold nanoparticles embedded in silica sol-gel matrix as an amperometric sensor for hydrogen peroxide. J Electroanal Chem. 2007b;608:52-8.

Maduraiveeran G, Ramaraj R. Potential sensing platform of silver nanoparticles embedded in functionalized silicate shell for nitroaromatic compounds. Anal Chem. 2009:81:7552-60.

Malik $\mathrm{P}$, Srivastava $\mathrm{M}$, Verma $\mathrm{R}$, et al. Nanostructured $\mathrm{SnO}_{2}$ encapsulated guargum hybrid nanocomposites for electrocatalytic determination of hydrazine. Mater Sci Eng C Mater Biol Appl. 2016;58:432-41. 
Matsuhisa H, Tsuchiya M, Hasebe Y. Protein and polysaccharide-composite sol-gel silicate film for an interference-free amperometric glucose biosensor. Colloids Surf B Biointerfaces. 2013;111:523-9.

Moghimi N, Mohapatra M, Leung KT. Bimetallic nanoparticles for arsenic detection. Anal Chem. 2015;87:5546-52.

Quan D, Shin W. A nitrite biosensor based on co-immobilization of nitrite reductase and viologen-modified chitosan on a glassy carbon electrode. Sensors. 2010;10:6241-56.

Quan D, Shim JH, Kim JD, et al. Electrochemical determination of nitrate with nitrate reductase-immobilized electrodes under ambient air. Anal Chem. 2005:77:4467-73.

Sabri YM, Ippolito SJ, Tardio J, et al. Gold nanospikes based microsensor as a highly accurate mercury emission monitoring system. Sci Rep. 2014;4:6741.

Sampath S, Lev O. Inert metal-modified, composite ceramic-carbon, amperometric biosensors: renewable, controlled reactive layer. Anal Chem. 1996;68:2015-21.

Wang YC, Cokeliler D, Gunasekaran S. Reduced graphene oxide/carbon nanotube/gold nanoparticles nanocomposite functionalized screen-printed electrode for sensitive electrochemical detection of endocrine disruptor bisphenol A. Electroanal. 2015;27:2527-36.

Wang N, Lin M, Dai H, et al. Functionalized gold nanoparticles/reduced graphene oxide nanocomposites for ultrasensitive electrochemical sensing of mercury ions based on thymine-mercury-thymine structure. Biosens Bioelectron. 2016; 79:320-6.

Zhang $Y$, Zeng GM, Tang L, et al. Electrochemical sensor based on electrodeposited graphene-Au modified electrode and nanoAu carrier amplified signal strategy for attomolar mercury detection. Anal Chem. 2015; 87:989-96.

Zhang MR, Chen X-Q, Pan G-B. Electrosynthesis of gold nanoparticles/porous GaN electrode for non-enzymatic hydrogen peroxide detection. Sens Actuators B: Chem. 2017;240:142-7.

Zhao Z, Sun Y, Li P, et al. Preparation and characterization of AuNPs/CNTs-ErGO electrochemical sensors for highly sensitive detection of hydrazine. Talanta. 2016;158:283-91

Zhou X, Wan J, Chu L, et al. Identification of sulfur fumed Pinelliae Rhizoma using an electronic nose. Pharmacogn Mag. 2014;10:S135-40.

\section{Submit your manuscript to a SpringerOpen ${ }^{\circ}$ journal and benefit from:}

- Convenient online submission

- Rigorous peer review

- Immediate publication on acceptance

- Open access: articles freely available online

- High visibility within the field

- Retaining the copyright to your article

Submit your next manuscript at $\gg$ springeropen.com 